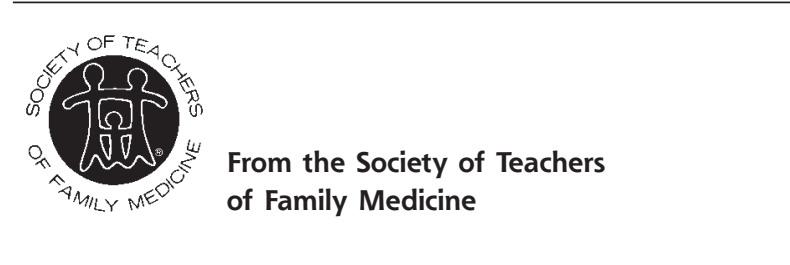

Ann Fam Med 2009;7:281-282. DOI: 10.1370/afm.1008.

\section{THE FAMILY MEDICINE CLERKSHIP CORE CONTENT CURRICULUM}

Family medicine clerkships across the country have developed into unique experiences, perhaps due to the breadth of knowledge and skills that family physicians possess. These differences give clerkship directors the autonomy to address regional variation in prevalence of diseases, supplement shortcomings in their medical schools' curriculums, and infuse their own preferences. However, these differences also limit our discipline's ability to describe what unique attributes we add to the curriculum, focus our national subject examination, and provide national curricular resource materials.

To address these limitations, STFM President Scott Fields, MD, with support from the STFM Board, created a task force of 9 members to define the core family medicine clerkship curriculum. The task force has representatives from the major stakeholders in the family of family medicine. The Council of Academic Family Medicine has endorsed this initiative as one of its priority projects, and the STFM Foundation provided the funding to support this work.

The task force was charged with determining what conditions should comprise the national family medicine curriculum. The Family Medicine Clerkship Core Content Curriculum (C4) is not a list of all of the patient presentations that family physicians competently manage, but rather a list of common presentations.

The C4 document contains an introduction outlining the value of the provision of primary care by family physicians; 3 sections of acute, chronic, and prevention content; a section on the major components of family medicine care; and a section of clinical skills. The purposes of a family medicine clerkship are to: (1) demonstrate the unequivocal value of primary care to any health care system; $(2)$ teach an approach to acute presentations commonly seen in the office setting $_{i}$ (3) teach an approach to the management of chronic illnesses that are commonly seen in the office setting $_{i}(4)$ teach an evidenced-based approach to a wellness visit for any age or gender patient ${ }_{i}(5)$ model the components of family medicine care; and (6) provide instruction in history taking, communication, physical examination, and clinical reasoning skills.
Accordingly, at the end of the family medicine clerkship, each student should be able to:

1. Discuss the value of the provision of primary care by family physcians to any health care system

2. Assess, formulate a differential diagnosis, and propose initial evaluation and management for patients with common acute presentations

3. Manage a chronic illness follow up visit for patients with common chronic diseases

4. Develop an evidence-based health maintenance plan for a patient of any age or either gender

5. Discuss the major components of family medicine care

6. Demonstrate competency in advanced historytaking, communication, physical examination, and critical thinking skills

The C4 Task Force created lists of specific topics to match these objectives. We held an open session at the STFM Predoctoral Conference in January 2009. A draft of the curriculum, including these lists, is available on the STFM Web site at http://www.stfm.org/ initiatives/core.cfm. The $\mathrm{C} 4$ task force has received feedback from many of our members, which has been greatly appreciated. We have modified the document based on that feedback. Changes made based on feedback include: (1) changing the focus from the patientcentered medical home to the components of family medicine care (2) capturing the complexity of family medicine; and (3) shortening the lists.

The patient-centered medical home is the current name for a practice that is patient-centered and whole person oriented, uses a team approach, eliminates barriers to access, uses integrated information systems, and focuses on quality. These characteristics have been long-standing principles of family medicine care. Initially, we proposed an objective and content for a section on the patient-centered medical home. We agreed with the feedback from our members that the name "patient-centered medical home" may change, but the principles of family medicine care will remain. So, although we mention the patient-centered medical home, the curriculum now focuses on knowledge of specific components of family medicine care, many of which are components of the patient-centered medical home.

We received feedback that we had not captured this concept of complexity in our first draft. Complexity is certainly a central theme of family medicine. The task force held several discussions trying to balance what is developmentally appropriate for a third-year student with the level of complexity that is family medicine. Always included were the concepts of how psychosocial issues interplay with health and illness. We are adding a small amount of complexity in 2 ways: 
drawing attention to multipurpose visits and including a multiple chronic illness presentation on the common chronic diseases list. We realize this is far less complexity that family physicians encounter.

Developing the lists has been the most difficult task. Most people who have provided feedback on the length of the lists have told us they are too long. We are shortening the lists.

At present, the task force is drafting objectives for each item on the acute presentation, chronic illness, and prevention visit lists; and the section on the components of family medicine care. At the STFM Annual Spring Conference, an open session was held on Friday May 1 to review progress and seek feedback. For more information or to follow the progress of this project, visit http://www.stfm.org/initiatives/core.cfm.

Heidi Cbumley, MD STFM FM C4 Task Force Chair

\section{CHANGE-OF-ADDRESS FORM FANMILY MEDICINE}

Please complete this form and mail to the following address or fax to Annals Circulation at 913-906-6080:

Annals of Family Medicine, Circulation Department, 11400 Tomahawk Creek Pkwy, Leawood, KS 66211-2680

Check if member of sponsoring organization:

$$
\begin{array}{lc}
\square \text { AAFP } & \square \text { ABFM } \square \text { STFM } \square \text { ADFM } \\
\square \text { AFMRD } & \square \text { NAPCRG } \square \text { CFPC }
\end{array}
$$

ID number from label on your journal cover

OLD Information (Please print.)

Name

Company (if applicable)

Address (Street plus Apt or Ste)

\begin{tabular}{ll}
\hline City & State \\
\hline Country & Postal Code (9-digit ZIP for US) \\
\hline Telephone & Fax \\
\hline E-Mail &
\end{tabular}

NEW Information (Please print.)

\begin{tabular}{ll}
\hline Name \\
\hline Company (if applicable) \\
\hline Address (Street plus Apt or Ste) \\
\hline City & \\
\hline Country & Postal Code (9-digit ZIP for US) \\
\hline Telephone & Fax \\
\hline E-Mail &
\end{tabular}

